\title{
Molecular Imaging in Tracking Tumor Stem-Like Cells
}

\author{
Tian Xia, ${ }^{1}$ Han Jiang, ${ }^{1,2,3,4}$ Chenrui Li, ${ }^{5}$ Mei Tian, ${ }^{1,2,3,4}$ and Hong Zhang ${ }^{1,2,3,4}$ \\ ${ }^{1}$ Department of Nuclear Medicine, Second Affiliated Hospital of Zhejiang University, School of Medicine, 88 Jiefang Road, \\ Hangzhou, Zhejiang 310009, China \\ ${ }^{2}$ Zhejiang University Medical PET Center, Zhejiang University, Hangzhou 310009, China \\ ${ }^{3}$ Institute of Nuclear Medicine and Molecular Imaging, Zhejiang University, Hangzhou 310009, China \\ ${ }^{4}$ Key Laboratory of Medical Molecular Imaging of Zhejiang Province, Hangzhou 310009, China \\ ${ }^{5}$ The School of Pharmacy, The Chinese University of Hong Kong, Hong Kong \\ Correspondence should be addressed to Hong Zhang, hzhang21@gmail.com
}

Received 27 December 2011; Accepted 10 February 2012

Academic Editor: Enzhong Li

Copyright ( 2012 Tian Xia et al. This is an open access article distributed under the Creative Commons Attribution License, which permits unrestricted use, distribution, and reproduction in any medium, provided the original work is properly cited.

Cancer remains a major public health problem in many countries. It was found to contain a subset of cancer stem cells (CSCs) that are capable of proliferation and self-renewal, and differentiation into various types of cancer cells. CSCs often display characteristics of chemotherapy resistance and radiotherapy resistance. Numerous putative biomarkers of CSCs are currently identified including CD133, CD44, CD24, ALDH (aldehyde dehydrogenase), and ABCG2. Interestingly, no single marker is exclusively expressed by CSCs. Thus, the various combinations of different biomarkers will be possible to identify CSCs, and considerable work is being done to recognize new ones. In order to demonstrate the mechanisms of resistance and response to therapy and predict the outcome as well as prognosis, the ways to track and identify CSCs will be extremely important. The technologies of molecular imaging will reveal mechanisms of cancer progression and provide visual targets for novel therapeutics. Limited studies were investigated on the detection of various types of CSCs by molecular imaging. Although the tracking of circulating CSCs is still hampered by technological challenges, personalized diagnosis and therapies of cancers are expected to be established based on increased understanding of molecular imaging of cancer stem-like cells biomarkers.

\section{Introduction}

The global burden of cancer is increasing, and cancer is a major public health problem in many parts of the world, including China. Based on the American Cancer Society cancer statistics, a total of 1,596,670 new cancer cases and 571,950 deaths from cancer, corresponding to more than 1500 deaths per day, are projected to occur in the United States in 2011 [1]. Among men cancers of the prostate, lung and bronchus, and colorectum will account for approximately $52 \%$ of all newly diagnosed cancers. Breast, lung and bronchus, and colorectum will be the three most commonly diagnosed types of cancers among women this year. Cancers of the lung and bronchus, prostate, and colorectum in men, and cancers of the lung and bronchus, breast, and colorectum in women continue to be most common causes of cancer death. These four cancers account for almost half of the total cancer deaths among men and women [1].
Cancer mortality remains high, despite the recent advances made in cancer treatment and diagnosis. One possible cause for therapeutic failure is that many malignant tumors contain a subset of tumor-initiating cells termed cancer stem cells (CSCs) when multipotency and selfrenewal have been demonstrated. The CSC model provides an attractive concept that help to explain why cancer cells resistant to chemo- and radiotherapies. There has been acceptance of the idea that the remaining tumor cells after anticancer therapy have a distinct molecular phenotype that confers resistance to the therapies $[2,3]$. Identification and purification of the CSC population from clinical samples and cell lines have been proven successfully based on the expression of a particular cell-surface marker, as well as by functional assays. The identification of CSC has undergone rapid development in recent years.

Side population (SP) technology has been widely used to identify the cancer stem-like cells by detection of the 
ability to efflux Hoechst 33342 dye through an adenosinetriphosphate-(ATP-) binding cassette (ABC) membrane transporter. In many tumors, SP cells are reported as enriched cells with tumorigenesis and are responsible for chemoresistance and tumor recurrence [4-6]. The current methods for isolation of putative CSCs depend on cell surface biomarkers and enzymatic activity detected by fluorescenceactivated cell sorter (FACS). Clarified understanding and eradication of CSCs, in turn, may improve the outcome of some cancer therapy $[3,7]$. One of the promising strategies is to track the CSCs and then target them for efficient treatments. Techniques required for real-time imaging and studies of tumor cells in viable fresh tissue or living animals are urgently needed.

Molecular imaging is a new and noninvasive strategy which can provide molecular and physiological information regarding cancer using various molecular-targeted imaging probes specific for cell surface biomarkers that are unique to cancer. It aims to visualize and quantify biological, physiological, and pathological processes on cellular and molecular levels. This has advantages over traditional methods, as they permit real-time tracking in vivo. Based on the biological characteristics of cancer stem cells, molecular imaging will provide a novel role for the visualization of cancer cells. Intravital imaging of CSCs could be of great importance for determining prognosis, as well as monitoring therapeutic efficacy and influencing therapeutic protocols. Cancer biomarker-based molecular imaging has become an essential element for cancer diagnosis. In most cases, the accuracy of predicting cancers depends on the specificity and signal sensitivity of molecular probes targeting genes or proteins involved in cancer growth and progression. In this paper, we will briefly discuss and summarize cancer stem biomarkers and the applications of the molecular imaging in tumor stem-like cells or tumor cells.

\section{Types of Cancer Stem Cells and Its Biomarkers}

CSCs have been defined as a subset of cancer cells with exclusive ability of self-renewal and to cause the heterogeneous lineages of cancer cells that comprise the tumor. Numerous putative markers are currently under investigation, and much work is being done to identify and characterize new marker. The experimental methods to identify CSCs have been developed so far as follows: (a) clonogenic assay; (b) sphere-forming assays; (c) assays to investigate the differentiation potency of isolated cells into the various differentiated cells. In addition to these analyses based on in vitro properties of CSCs, the existence of CSCs has been demonstrated by tumor initiation assays, in which the primary human tumor cells were transplanted into NOD/SCID mice [8-10] (Figure 1). Cell surface markers and enzymatic activity detected by FACS have been widely used for the prospective isolation of putative CSCs. Here, the biomarkers to identify CSCs in different types of tumor models are investigated.
2.1. Hematopoietic System: Acute Myelogenous Leukemia (AML). In 1994, Lapidot et al. showed that leukemia can be initiated in mice using a single tumorgenic cell. It implied that a single or a few malignant cells can produce tumors [11]. These leukaemia-initiating cells were found to be $\mathrm{CD} 34^{+} \mathrm{CD}^{-} 8^{-}$on the basis of the cell-surface-marker expression. Subsequently, Bonnet et al. also demonstrated that the cell capable of initiating human AML in nonobese diabetic mice with severe combined immunodeficiency disease (NOD/SCID mice), termed the SCID leukemiainitiating cell, was exclusively $\mathrm{CD} 34^{+} \mathrm{CD} 38^{-}$[12]. After the identification of rare CSCs in leukemia, numbers of molecular markers for detecting CSCs in solid tumors have also been identified. The models that have been devised to describe the CSCs are as follows.

\subsection{Solid Tumors: Brain/Breast/Lung/Colorectal/Prostate/ Pancreas/Liver}

2.2.1. Brain. Brain tumors are the leading cause of cancer mortality in children and remain incurable despite advances in surgery and adjuvant therapies [1]. Singh et al. reported that only the $\mathrm{CD}_{133^{+}}$brain tumor fraction contains cells that were capable of tumor-initiation in NOD-SCID mouse brains [13]. They used a xenograft assay that identified human brain tumor initiating cells that initiate tumors in vivo. In their studies, injection of $10^{5} \mathrm{CD} 133^{-}$cells did not form a tumor, whereas only $100 \mathrm{CD} 133^{+}$cells produced the patient's original tumor. This identification of an in vivo tumor-initiating cell from human brain tumors provided a powerful tool to investigate the tumorigenic process in the central nervous system. Interestingly, Chiao et al. suggested that $\mathrm{CD}_{133^{+}}$glioblastoma stem-like cells (GSCs) and CD133- GSCs shared similar efficacy in tumor formation but showed distinct intratumor vasculature [14]. Compared with CD133- GSC, a highly vascularized anaplastic tumor was found in $\mathrm{CD}_{133^{+}}$GSC-derived tumor xenografts. Both in vitro and in vivo subsets of $\mathrm{CD}_{133^{+}}$GSC but not CD133- GSC were capable of vascular smooth muscle-like cell differentiation. The detection of endothelium-associated CD31 gene and differentiation of vascular-like cells suggest that GSCs may contribute to form vessel-like structures and provide a blood supply for glioblastoma cells.

Additionally, Tabuse et al. found high expression of the HOXD9 gene transcript in glioma cell lines and human glioma tissues [15]. They suggested that HOXD9 would be a novel marker of GCSCs and cell proliferation and/or survival factor in gliomas and glioma cancer stem-like cells, and a potential therapeutic target (HOX genes encode a family of homeodomain-containing transcription factors involved in the determination of cell fate and identity during embryonic development. They also behave as oncogenes in some malignancies).

2.2.2. Breast. Breast cancer is the most frequently diagnosed cancer and the leading cause of cancer death among females, accounting for $23 \%$ of the total cancer cases and $14 \%$ of the cancer deaths, based on the GLOBOCAN 2008 estimates [1, 


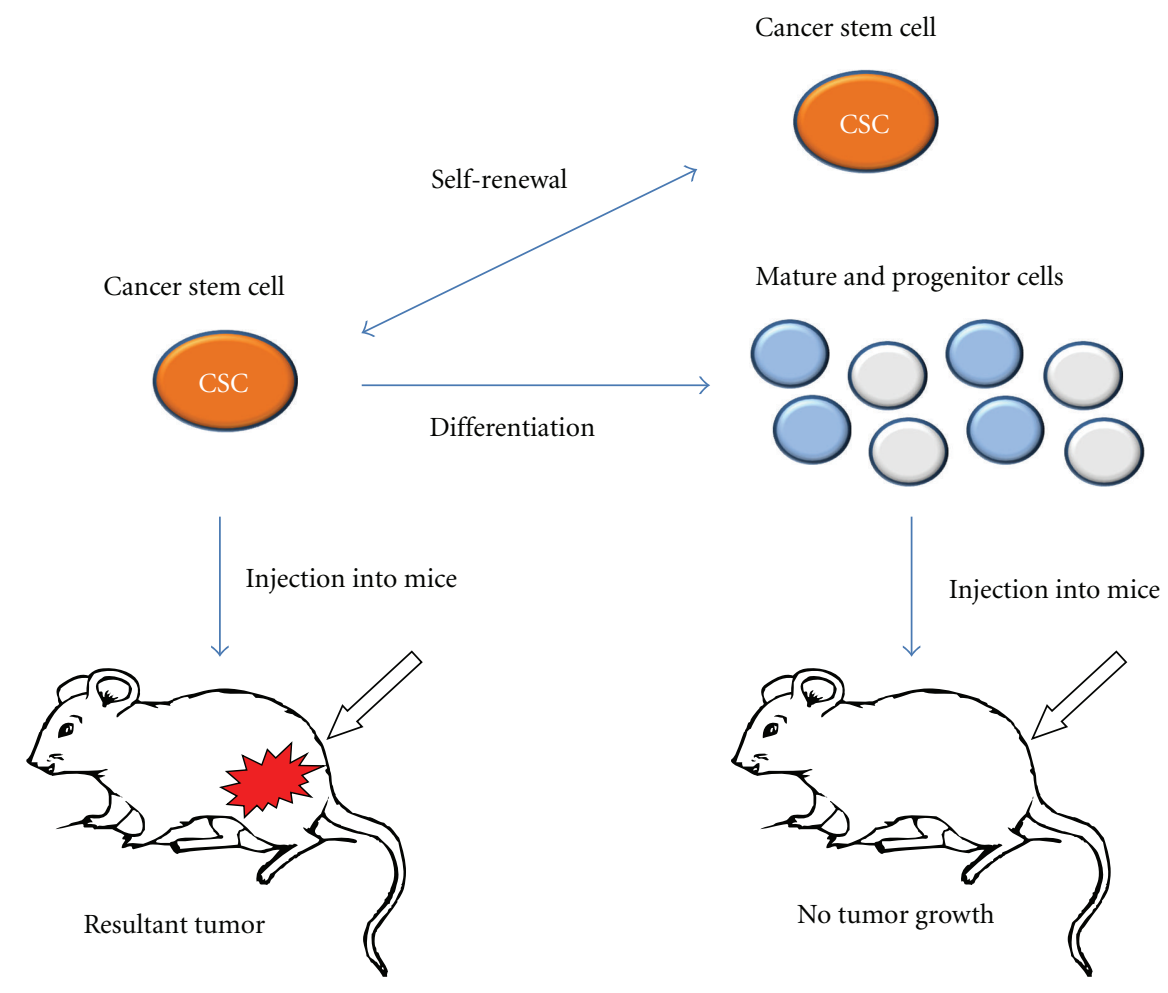

FIGURE 1: Three phenotypes of CSCs: self-renew, multipotentiality, and tumor-initiating capacity. Self-renewal: single-cell culture sphereforming assay. Differentiation: flow cytometric analysis of differentiation markers and loss of stem cell markers. Tumor-initiating properties were investigated by injection of CSCs in NOD/SCID mice. The most crucial standard for a CSC is its ability to reinitiate a serially transplantable tumor that recapitulates the original heterogeneity and tumor histology. Using this standard, many so-called CSCs reported so far are based on correlative studied rather than being true CSCs.

16]. In the United States, breast cancer is expected to account for $30 \%(230,480)$ of all new cancer cases among women in 2011 [1]. Through analysis of cell surface markers and xenotransplant models, a subpopulation of putative human breast cancer stem cells that is $\mathrm{CD} 24^{-} / \mathrm{CD} 44^{+}$and bears high aldehyde dehydrogenase isoform 1(ALDH1) activity has been isolated in clinical samples of breast cancer tissues [3]. These cells are regarded as having the most prominent tumor-initiating activity. Cells with aldehyde dehydrogenase (ALDH) activity isolated from normal human breast have phenotypic and functional characteristics of mammary stem cells. Analyzing the expression of ALDH1 in hundreds of human breast carcinomas from two independent tumor sets indicated poor clinical outcome [17]. These findings provide support for the "cancer stem cell hypothesis" and further indicated that ALDH1 was a marker of stem/progenitor cells of the normal human breast and breast carcinomas. The ALDH1-positive cell population had a small overlap with the previously described cancer stem cell, CD $44^{+} / \mathrm{CD} 24^{-} / \mathrm{lin}-$ phenotype [18].

The overlap represented approximately $1 \%$ or less of the total cancer cell population, which bears both phenotypes appeared to be highly enriched in tumorigenic capability. It was found that as few as 20 cells were able to generate tumors. Since ALDH is also expressed in hematopoietic and neuronal stem cells, this marker may prove useful for the detection and isolation of cancer stem cells in other malignancies, thus facilitating the application of cancer stem cell biology to clinical practice. In breast CSCs, it was also showed that the activity of TAZ, a transducer of the Hippo pathway, is required to sustain self-renewal and tumorinitiation capacities. TAZ protein levels and activity, which is promoted by the epithelial-mesenchymal transition (EMT), are elevated in prospective CSCs and in poorly differentiated human tumors, which have prognostic value [19]. The Hippo transducer TAZ confers cancer stem cell-related traits on breast cancer cells.

2.2.3. Lung. Lung cancer is the third most commonly diagnosed type and third most common cause of cancer death both in male and female [1]. Similar to the limited understanding of lung stem cell biology, the identity of the cell of origin in lung tumorigenesis is also largely unknown. Lung cancer contains a rare population of $\mathrm{CD} 133^{+}$cancer stem-like cells able to self-renew and generates an unlimited progeny of nontumorigenic cells. Molecular and functional characterization of such a tumorigenic population may provide valuable information to be exploited in clinic [20]. It was found that human lung CSCs also express ABCG2, ckit receptors, embryonic markers (SSEA-3, TRA-1-81, Oct4 , and nuclear $\beta$-catenin), and low levels of the cytokeratins 8/18 (CK8/18) [21, 22]. 
2.2.4. Colorectal Cancer. Colorectal cancer is the third most commonly diagnosed cancer in males and the second in females [1]. Colorectal cancer incidence rates are rapidly increasing in several areas historically at low risk, of which possible reasons are a combination of factors including changes in dietary patterns, obesity, and an increased prevalence of smoking.

The existence of human colon cancer tumor-initiating cells was demonstrated by O'Brien et al. [10]. They used the renal capsule transplantation in immunodeficient NOD/ SCID mice to identify a human colon cancer-initiating cell (CC-IC), which was CD133+. However, the CD133- cells that comprised the majority of the tumor were unable to initiate tumour growth. They calculated by limiting dilution analysis that there was one CC-IC in $5.7 \times 10^{4}$ unfractionated tumor cells, whereas there was one CC-IC in $262 \mathrm{CD} 33^{+}$cells, representing $>200$-fold enrichment. CCICs within the $\mathrm{CD}_{133^{+}}$population were able to maintain themselves as well as differentiate and reestablish tumor heterogeneity upon serial transplantation. The identification of colon cancer stem cells and the existence of tumorigenic and nontumorigenic cells within colon cancers suggested that they must target the cancer stem cells for therapeutic strategies to be effective.

Simultaneously, tumorigenic cells in colon cancer were included in the high-density $\mathrm{CD}_{133^{+}}$population, which accounted for about $2.5 \%$ of the tumor cells [9]. The original tumor in NOD/SCID mice can be reproduced by injection of colon cancer $\mathrm{CD}_{133^{+}}$cells. Purified CD133 and carcinoembryonic antigen-positive $\left(\mathrm{CEA}^{+}\right)$colon cancer cells were unable to transfer the tumor into immunocompromised mice, and the tumorigenic population in colon cancer is restricted to $\mathrm{CD}_{133^{+}}$cells. Importantly, CC-ICs need to remain undifferentiated to maintain tumorigenic potential. During the in vivo passages, the tumors were serially transplanted for several generations, and CD133+ cells did not lose their tumorigenic potential. Instead, in each of the tumors they observed progressively faster tumour growth without significant phenotypic alterations. Therefore, the small number of undifferentiated tumorigenic $\mathrm{CD}_{133^{+}}$cells should be the target of future therapies.

Using multiple genetic markers, researchers also had evaluated the clinical significance of circulating tumor cells as a prognostic factor for overall survival (OS) and diseasefree survival (DFS) in the peripheral blood (PB) of patients with colorectal cancer Dukes' stages B and C who had undergone curative surgery. OS and DFS of patients who were positive for CEA/CK/CD133mRNA were significantly worse than those of patients who were negative for these markers. Detection of CEA/CK/CD133 mRNA in PB is a useful tool for determining which patients are at high risk for recurrence and poor prognosis [23]. Moreover, in human colorectal cancer, CSCs are also defined using CD166, CD44, and CD24 cell-surface markers [24, 25].

The CSC theory suggests that the actual tumorigenic capacity of individual cancer cells may be influenced by homeostatic signals derived from their microenvironment. It was observed that high Wnt activity functionally designates the colon CSC population [26]. Nevertheless, the current data lend strong support to the influence of the niche on CSC maintenance.

2.2.5. Prostate. Prostate cancer will account for $29 \%$ (240, 890 ) and be most commonly diagnosed cancer in men in United States according to the American Cancer Society in 2011 [1]. There continues to be a need for new diagnostic markers and potential new therapeutic targets in prostate cancer. Studies suggested that high ALDH activity and coexpression of CD44 $\left(\mathrm{ALDH}^{\mathrm{hi}} \mathrm{CD} 44^{+}\right)$cells exhibited a higher proliferative, clonogenic, and metastatic capacity in vitro and demonstrated higher tumorigenicity capacity in vivo in prostate cancer cell line. However, low ALDH activity and CD44-negative ( $\mathrm{ALDH}^{\mathrm{lo}} \mathrm{CD} 44^{-}$) cells were able to develop tumors, albeit with longer latency periods. In their study, ALDH activity and CD44 did not appear to identify prostate cancer stem cells; however, they did reveal increased tumorigenic and metastatic potential, indicating their potential importance for further exploration [28].

Rajasekhar et al. identified a minor subset of stem-like human prostate tumour-initiating cells (TICs) that do not express prostate cancer markers, such as androgen receptor or prostate-specific antigen [29]. The cells represent an undifferentiated subtype of basal cells and can be purified from prostate tumors based on coexpression of the human pluripotent stem cell marker TRA-1-60 with CD151 and CD166. Such triple-marker-positive TICs possess stem cell characteristics and multipotency as demonstrated by in vitro sphere formation and in vivo tumor initiation, respectively.

2.2.6. Pancreas. Pancreatic adenocarcinoma continues to be one of the deadliest cancer-related diseases in the world [30]. Little progress has been made since the past introduction of the chemotherapeutic agent gemcitabine, which remains the first-line chemotherapeutic agent in pancreatic cancer. The prognosis of patients diagnosed with pancreatic cancer remains extremely poor [31]. Emerging evidence suggests that the majority of pancreas tumors display vital functional heterogeneity in their respective cell populations. However, a small subpopulation of tumor cells that have acquired the same somatic mutations as the other tumor cells with epigenetically distinct is responsible for tumor initiation, growth, and metastasis [32, 33].

Researchers identified a highly tumorigenic subpopulation of pancreatic cancer cells expressing the cell surface markers CD44, CD24, and epithelial-specific antigen (ESA) using a xenograft model of immunocompromised mice for primary human pancreatic adenocarcinomas [34]. Pancreatic cancer cells expressing the cell surface markers CD44, CD24, and ESA had at least a 100-fold increased tumorigenic potential compared with nontumorigenic cells. The $\mathrm{CD} 44^{+} \mathrm{CD} 24^{+} \mathrm{ESA}^{+}$pancreatic cancer cells showed the stem cell properties of self-renewal, the ability to produce differentiated progeny, and increased expression of the developmental signaling molecule sonic hedgehog $(\mathrm{SHH})$.

More recent data suggested an abundant expression of ALDH-1 in normal pancreas tissue [35]. It was found that a subset of adult centroacinar cells and terminal ductal epithelial (CA/TD) cells were characterized by high levels 
TABLE 1: Comparison of the biomarkers of CSC and normal stem cell.

\begin{tabular}{|c|c|c|c|c|}
\hline Cancer type & CSC marker & Normal stem cell & Marker & References \\
\hline \multirow[t]{2}{*}{ Acute myelogenous leukemia } & $\mathrm{CD}_{3} 4^{+} \mathrm{CD} 38^{-}$ & Mouse embryonic stem cell & Oct-4 & {$[64]$} \\
\hline & & & SSEA-1 & {$[65]$} \\
\hline Glioma & Nestin, HOXD9 & Human embryonic stem cell & $\begin{array}{l}\text { SSEA-3 } \\
\text { SSEA-4, Oct-4 }\end{array}$ & {$[65]$} \\
\hline Breast & $\begin{array}{l}\text { ALDH } 1, \text { TAZ } \\
\mathrm{CD} 44^{+} / \mathrm{CD} 24^{-} / \mathrm{lin}^{-}\end{array}$ & & $\begin{array}{l}\text { TRA-1-60 } \\
\text { TRA-1-81 }\end{array}$ & {$[65]$} \\
\hline Colon & CD166 & Neural stem cell & CD133 & {$[66]$} \\
\hline Prostate & $\begin{array}{l}\text { TRA-1-60 } \\
\text { CD151, CD } 166\end{array}$ & & Nestin & {$[66]$} \\
\hline Pancreas & ESA & Hepatic stem cell & EpCAM & {$[43]$} \\
\hline Liver & $\begin{array}{l}\text { CD90, EpCAM } \\
\text { CD13 }\end{array}$ & Mammary stem cell & $\mathrm{CD} 49 \mathrm{f}^{+} \mathrm{EpCAM}^{\text {neg-low }}$ & {$[67]$} \\
\hline Breast, liver, and pancreas & ALDH & & ALDH1 & {$[17,68]$} \\
\hline $\begin{array}{l}\text { Glioma, lung, colon, pancreas, and } \\
\text { liver }\end{array}$ & CD133 & & & \\
\hline Pancreas, colon, and liver & $\mathrm{CD} 24, \mathrm{CD} 44$ & & & \\
\hline Breast, pancreas, and lung & ABCG2 & & & \\
\hline
\end{tabular}

CD49f: $\alpha 6$ integrin; Lin: Lineage surface antigen; SSEA: stage-specific embryonic antigen.

of ALDH1 enzymatic activity. CA/TD cells carry significant progenitor capacities and may contribute to the maintenance of tissue homeostasis in adult mouse pancreas. Subsequently, Kim et al. sought to determine the relationship of ALDH and CD133 whose marker best enriches for pancreatic TICs and the sufficiency of $\mathrm{ALDH}^{\mathrm{hi}}$ and $\mathrm{ALDH}^{\mathrm{lo}}$ cell populations for tumor-initiation when enriched or depleted of cell populations also expressing CD133 [36]. Finally, they demonstrated that cell populations enriched for high ALDH activity alone were more efficient and fulfill the major criteria of a CSC and efficiently recapitulate the phenotype of the original tumor independent of CD133 cell surface expression, using a strict, direct xenograft tumor system and limiting dilutions of sorted human pancreatic cancer cells injected into NOD/SCID mice [36].

It was also suggested that SP cells were enriched in CSCs of pancreas cancer and validated an intriguing regulatory mechanism of the cancer stem cell-related phenotypes, which could represent a novel therapeutic target $[4,37]$.

2.2.7. Liver. Hepatocellular carcinoma (HCC) accounts for over $90 \%$ of primary liver cancer in adults. The firstline treatment for HCC is liver transplantation or surgical resection [37, 38]. However, most HCCs are inoperable because patients present at advanced stages. Even after surgical resection, the long-term prognosis of HCC remains unsatisfactory due to high recurrence rates. Recently, there has been mounting evidence in support of the existence of CSCs in hepatocellular carcinoma. CD24 was found to be a functional liver tumor-initiating cell (T-IC) marker. CD24 ${ }^{+}$ HCC cells were found to be critical for the maintenance, self-renewal, differentiation, and metastasis of tumors and to significantly impact patients' clinical outcome [39]. In liver, CSCs can also be identified by several other cell markers, including CD44, CD133, CD90, CD13, EpCAM, OV6, and
ALDH enzymatic activity, or by selecting for SP cells which express an adenosine triphosphate-binding cassette (ABC) membrane transporter, such as MDR1 and ABCG2 [40]. However, generally accepted markers of CSCs in HCC have not been identified.

In summary, recent studies indicate that the expression of the surface markers is not suitable as a universal signature to detect CSCs in cells derived from different tumor types. It is likely that a panel of markers will be required to assess the presence of reliable and true CSCs in tumors. Although the list of CSC markers is not yet finished, a method to isolate and substantially enrich CSCs for cancer research is provided (Table 1).

\section{Imaging of Cancer Stem-Like (or Cancer) Cells}

Noninvasive molecular imaging technology is an effective and novel approach to visualize living cells in vivo. It also plays a critical role in tracking the location and activity of CSCs [41]. Now that CSCs are being identified and characterized in different tumor types, they are postulated to be responsible for tumor development, metastasis, and relapse after conventional therapies. To date, limited studies were investigated on the detection of various types of CSCs by molecular imaging methods (Table 2 ).

Examples will be given for the identified biomarkers of the tumor stem-like (or tumor) cells with molecular imaging techniques. Specifically, the feasibility of molecular imaging of prostate stem cell antigen-(PSCA-) positive prostate cancer was evaluated using an intermediate size antibody fragment by micropositron emission tomography (microPET) imaging [42], cell tracking with magnetic resonance imaging (MRI) after the hepatic progenitor cells labeled with EpCAM microbeads [43], CD133-specific monoclonal 
TABLE 2: Molecular imaging in tracking tumor stem-like cells.

\begin{tabular}{lccl}
\hline Imaging agent & $\begin{array}{c}\text { Molecular } \\
\text { imaging }\end{array}$ & Biomarker & Model \\
\hline${ }^{64}$ Cu-ATSM & PET & CD 133 & Colon cancer \\
Antibody magnetic microbead & MRI & ESA & Liver cancer \\
HA-MNCs & MRI & CD44 & Breast cancer \\
Antibody AC133.1 & FMT & CD133 & CD133-overexpressing glioblastoma \\
Optical bifusion reporter genes & BLI & CD44 & Breast cancer \\
GSC-targeting peptide & BLI & Nestin & Glioma \\
199b Luc-1 & BLI & CD133 & Medulloblastoma tumor \\
Adv5-199b & PET/CT & & \\
\hline
\end{tabular}

antibody AC133.1 used for quantitative fluorescence-based optical imaging of mouse xenograft models [44], and so on.

3.1. Positron Emission Tomography (PET). PET imaging is a highly sensitive system that has advantages over traditional methods, as it permits noninvasive, real-time tracking in vivo. To our knowledge, few published studies were found to track the CICs in cancers with PET imaging. We will give an example of a generated stem cell surface marker specific probe to prostate cancer by micro-PET imaging. In the human prostate cancer LAPC-4 xenograft model, a number of candidate molecules were identified with high expression using representational difference analysis (RDA), a PCR-based subtractive hybridization strategy [45, 46]. One promising candidate, PSCA, is a prostate-specific cell surface antigen expressed strongly in both androgen-dependent and -independent LAPC-4 tumors. Elevated levels of PSCA were correlated with increased tumor stage, grade, and androgen independence [47]. PSCA located at chromosome 8, band $\mathrm{q} 24.2$, is a prostate-specific gene, encoding a 123-aa protein with an amino-terminal signal sequence, a carboxyl-terminal GPI-anchoring sequence, and multiple N-glycosylation sites [46]. Researchers had isolated and characterized a series of monoclonal antibodies directly against PSCA. The localization of PSCA had been detected using these antibodies.

Leyton et al. revealed a humanized radioiodinated minibody as a PET imaging agent for the detection of PSCAexpressing tumors [42]. Visualization of PSCA-positive prostate cancer is feasible using an intermediate size antibody fragment at 21 hours. The genetically engineered radioiodinated ( ${ }^{124} \mathrm{I}$ or $\left.{ }^{131} \mathrm{I}\right) 2 \mathrm{~B} 3$ minibody as a novel antibody fragment for specific targeting and potential PET imaging agent for PSCA-expressing prostate cancers was introduced [48]. Then an affinity-matured minibody that ranked second in affinity for PET imaging of PSCA-expressing tumors was selected as the best tracer [49]. Currently, this candidate is under development for evaluation in a pilot clinical imaging study. Interestingly, two antibodies, anticlaudin 4 and anti-PSCA, were radio-labeled with iodine $125\left({ }^{125} \mathrm{I}\right)$ for imaging pancreatic cancer xenografts in mice using gamma scintigraphy and single-photon emission computed tomography-computed tomography (SPECT/CT). It has been demonstrated that they are promising as radiodiagnostic and possibly radiotherapeutic agents for human pancreatic cancers [50]. Antibodies or their constituent parts can be conjugated with radionuclides to carry them into tumors specifically and effectively. Similar to the specific normal stem cell biomarker detected in prostate cancer, which was used as early diagnosis marker in prostate cancer, tracking the CSCs biomarkers by PET imaging is also promising.

${ }^{64} \mathrm{Cu}$-diacetyl-bis (N4-methylthiosemicarbazone) $\left({ }^{64} \mathrm{Cu}\right.$ ATSM), a PET imaging agent, accumulated in regions of $\mathrm{CD}_{133^{+}}$high expression, which are then killed by radiation, resulting in a decrease of the percentage of $\mathrm{CD} 133^{+}$cells [51]. In vivo (colon 26-bearing mice) studies showed that ${ }^{64} \mathrm{Cu}$-ATSM treatment inhibited tumor growth. The percentage of $\mathrm{CD}_{133}{ }^{+}$cells and metastatic ability in ${ }^{64} \mathrm{Cu}-$ ATSM-treated tumors was decreased compared with that in control animals. ${ }^{64} \mathrm{Cu}$-ATSM could be a potential internal radiotherapy agent affecting the tumor's hypoxic regions with a high density of $\mathrm{CD}_{133^{+}}$cells, designated as CSCs. Therefore, tracking CSCs biomarkers and evaluating therapy efficiency are feasible and attractive. Further studies with more kinds of CSCs biomarkers would be needed to clarify the precise applications.

3.2. Magnetic Resonance Imaging (MRI). Magnetic resonance imaging is a noninvasive modality and can provide information on the anatomy, function, and metabolism of tissues in living subjects with no ionizing radiation. This imaging technique is increasingly performed in clinical diagnostics. Epithelial cell adhesion molecule (EpCAM) also known as epithelial-specific antigen (ESA) or CD326, a cell surface antigen, is found on liver CSCs, on hepatic progenitor cells including human hepatic stem cells (hHpSCs) and hepatoblasts (hHBs), and on proliferating epithelial cells in other tissues. McClelland et al. have evaluated the feasibility of cell tracking with MRI after the hepatic progenitor cells labeled with EpCAM microbeads before or after transplantation. Then the transplanted hHpSCs could be monitored and counted repeatedly in the same host by injection of the labeled MRI probe [43]. Additionally, magnetic iron microbeads coupled with HEA-125 monoclonal antibody against the epithelial cell adhesion molecule, abbreviated as EpCAM microbeads, have been developed primarily for the positive selection or depletion of EpCAM-positive cells. The magnetic labeling methodology is applicable to other 
surface antigens for which antibody magnetic microbeads are available [43]. Antibodies or their constituent parts can be conjugated with nanoparticles or other substances, to carry them more specifically and effectively into tumors. The biological effects of monoclonal antibodies are supposed to be possible if targeting antigens are present in cancer stemlike cells [52].

CD44 is a cell surface glycoprotein overexpressing in breast CSCs and plays an important role in promoting cancer cell proliferation, invasion, and tumor-associated angiogenesis [53]. First, researchers synthesized pyrenyl HA (Py-HA) conjugates as CD44-targetable surfactants capable of simultaneously encapsulating magnetic nanocrystals and targeting CD44 using HA and 1-pyrenebutyric acid (Py). Finally, Py-HA conjugates and magnetic nanocrystals were used to formulate HA-MNCs. Their study suggested that HA-MNCs can be a potent cancer-specific molecular imaging agent for effective diagnosis of CD44-overexpressing breast cancer via MR imaging [53]. Furthermore, CGrich duplex containing prostate-specific membrane antigen (PSMA) aptamer-conjugated thermally cross-linked super paramagnetic iron oxide nanoparticles (TCL-SPIONs) was reported as prostate cancer-specific nanotheranostic agents [54]. These agents were capable of prostate tumor detection in vivo by MRI and selective delivery of drugs to the tumor tissue, simultaneously.

3.3. Optical Imaging. CD133/prominin (AC133) has been identified as a CSC marker in a variety of tumors. Tsurumi et al. showed that CD133-specific monoclonal antibody AC133.1 was used for quantitative fluorescence-based optical imaging of mouse xenograft models [44]. Near-infrared fluorescence molecular tomography (FMT), a highly sensitive and fully quantitative technology, was applied as the in vivo imaging modality. Imaging worked well using CD133 overexpressing cell line however, the implanted xenograft HCT116 cells, which express CD133 at an endogenous level, had limitations. The lower CD133 expression level of the HCT116 wild-type tumors led to a generally lower signal to noise ratio compared to CD133-overexpressing tumors. They provided the first evidence that noninvasive antibodybased in vivo imaging of tumor-associated CD133 is feasible and that CD133 antibody-based tumor targeting is efficient.

In breast cancer, it was demonstrated that with noninvasive imaging approaches, as few as $10 \mathrm{CD}_{4} 4^{+}$cells of stably labeled breast cancer stem cells (BCSCs) could be tracked in vivo by bioluminescence imaging (BLI) [41]. Imaging revealed that $\mathrm{CD} 44^{+}$cells from both primary tumors and lung metastases were highly enriched for tumor-initiating cells. The BCSCs were tagged through expression of optical bifusion reporter genes to facilitate their visualization in the living human-in-mouse breast cancer xenograft model in NOD/SCID mice. Such reporters included firefly luciferase (Luc) for whole-body tracking of cells via BLI and fluorescent proteins. In order to label BCSCs, dual-function BLIfluorescent reporter constructs constituting the Luc coding sequence (Luc2) fused to that of fluorescent proteins were used. They fused Luc2 to enhanced GFP (eGFP) or the red fluorescent protein td-Tomato (Tom), which improved detection in vivo relative to GFP. They established optimized parameters to transduce primary or passaged BCSCs with lentiviral vectors encoding Luc2-eGFP (L2G) or Luc2-Tom (L2T) fusion genes; thereby one cell in vitro and minimum of 10 cells of labeled BCSCs could be noninvasively visualized at 16 hours after implantation, thus greatly enhancing the accuracy and efficiency of tumorigenic assays compared with traditional monitoring assay. This study implied that the optimized strategy for labeling BCSCs with optical reporter genes can be applied to studies with CSCs in other tumors such as colon cancer, brain tumor, head-and-neck cancer, and leukemia, and to evaluate other putative CSC markers (e.g., CD24, CD133, EpCAM, ALDH1, etc.).

In addition, Vlashi et al. demonstrated that reduced $26 \mathrm{~S}$ proteasome activity is a general feature of CICs for human glioma and breast cancer cells that can easily be exploited to identify, track, and target them in vitro and in vivo [55]. A fluorescent protein (ZsGreen) is a target of the $26 \mathrm{~S}$ proteasome. The fluorescent positive cells had increased sphere-forming capacity, expressed CSC markers, and lacked differentiation markers in vitro. When injected into nude mice, ZsGreen-positive cells were approximately 100-fold more tumorigenic than the opposite cells. It was required approximately $100 \mathrm{ZsGreen-positive} \mathrm{cells} \mathrm{to} \mathrm{form} \mathrm{tumors} \mathrm{in}$ vivo. They proposed that ZsGreen-positive cells need to be further purified to obtain a pure CSC population. Tracking of CICs by fluorescence imaging in vivo may facilitate the search for novel therapeutic approaches that improve radiation therapy outcome.

Nestin, one of the most reliable stemness markers, is used to evaluate the identity of normal neural stem cells and glioma stem cells (GSCs). Samuel Beck et al. isolated a GSCtargeting (GSCT) peptide that demonstrated selective binding isotypes of Nestin proteins specifically expressed in GSCs. In human glioblastoma tissue specimens, the fluorescenceconjugated GSCT peptide could visualize putative GSC populations, showing its possible use as a diagnostic agent (Figure 2). Intravenously injected GSCT peptide effectively penetrated into tissues, specifically accumulated in gliomas that arise from implantation, and predominantly targeted Nestin-positive cells in these tumors (Figure 3) [27].

3.4. Multimodal Imaging. Molecular imaging of cancers has been characterized based on the sensitivity and selectivity of a single cancer probe targeting a cancer biomarker of a specific cancer cell line. The goal of multimodality imaging is to combine the best features of separate modalities. Researchers had designed a multimodal nanoparticlebased simultaneously multiple aptamers and RGD targeting (SMART) cancer probe targeting multiple cancer biomarkers to enhance the specificity and signal sensitivity for various cancers. The SMART probe was conjugated to a multimodal nanoparticle that is capable of concurrent fluorescence, MRI, and radionuclide imaging. Unlike a single aptamer or peptide-conjugated multimodal cancer probe targeting a single cancer biomarker, the multimodal SMART cancer probe simultaneously targets multiple cancer biomarkers in various cancer cells, resulting in enhanced targeting efficacy and signals [56]. 

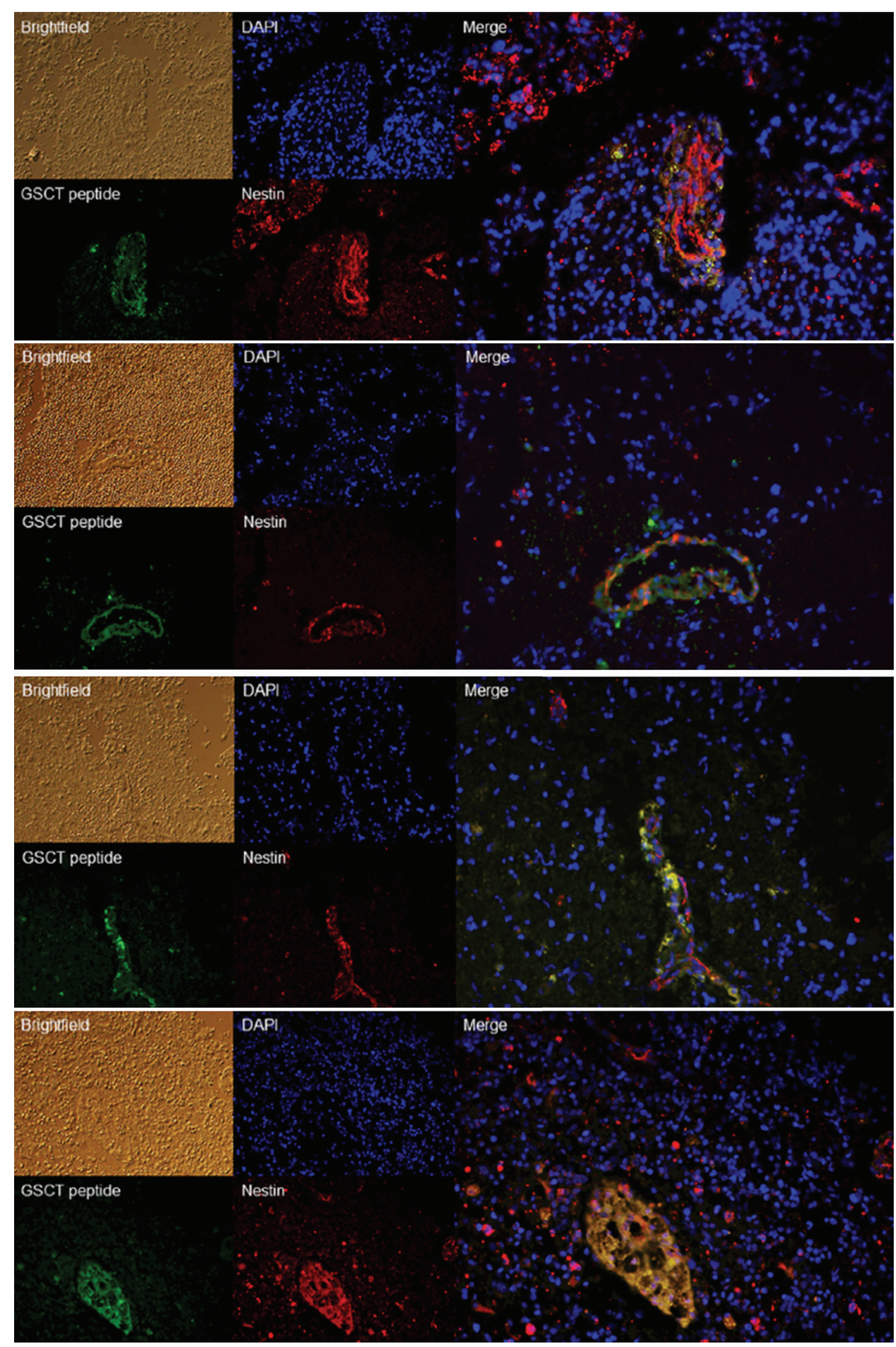

FIGURE 2: GSCT selectively binds Nestin-positive tumor cells in human GBM tissues. Paraffin-embedded human GBM tissue sections were stained with a biotinylated-GSCT (B-GSCT) peptide (Green) and Nestin antibody (Red). This immunofluorescence analysis revealed that most B-GSCT peptide-targeting tumor cells are colocalized with Nestin-positive tumor cells [27]. With reprint permission from Elsevier.

Garzia et al. demonstrated that miR-199b-5p overexpression blocks expression of several CSC genes and impairs the engrafting potential of medulloblastoma tumor (MB) stem-cell-like $\left(\mathrm{CD}_{133^{+}}\right)$subpopulation of cells in the cerebellum of nude mice. They used PET-CT fusion imaging to investigate the relationship between miRNAs targeting the MB tumors. The expression of miR199b-5p can deplete this tumor cell compartment, indicating the use of miRNA as an interesting therapeutic approach for the targeting of CSCs in brain tumors [57].

An important recent development is the concept of multimodality fusion reporter systems. Researchers have described fusion modality reporter genes for whole mouse body fluorescent, bioluminescent, and nuclear imaging [58]. 


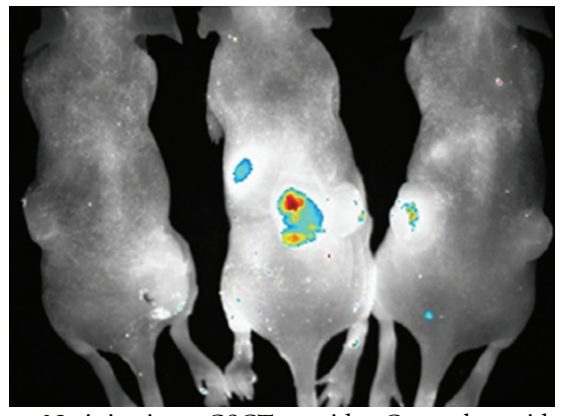

No injection GSCT peptide Control peptide

(a)

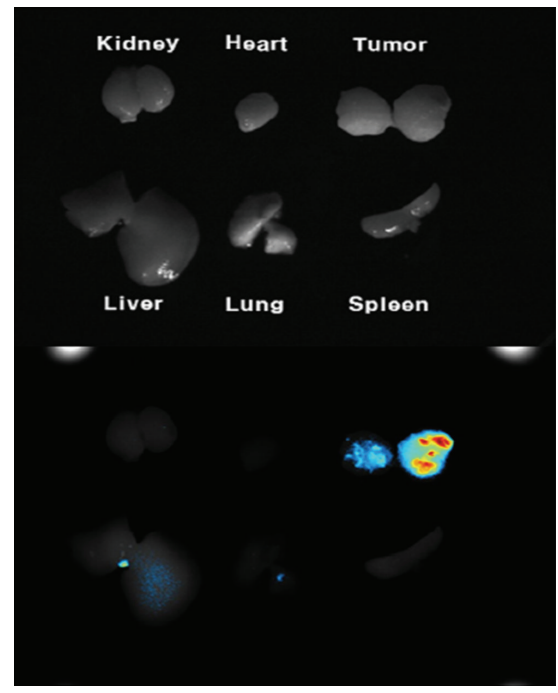

(c)

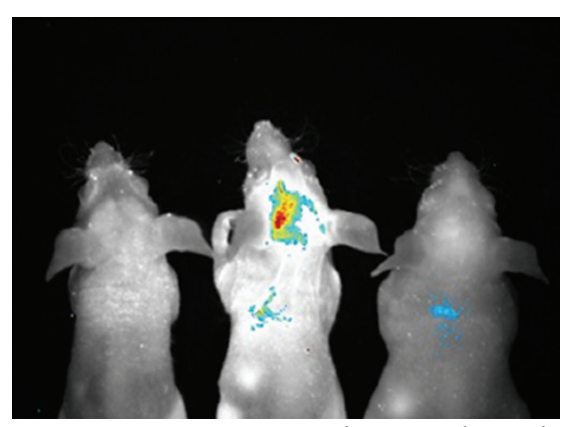

No injection GSCT peptide Control peptide

(b)
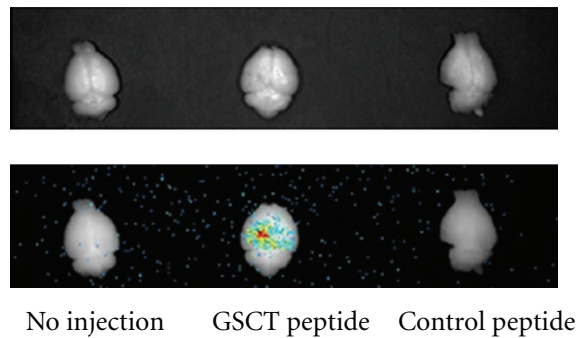

(d)

FIgURE 3: Homing of GSCT peptide to GSC-derived tumors in vivo [27]. (a) In vivo biodistribution of GSCT peptide was examined by intravenous injection of Q-dot 800-conjugated GSCT (QGSCT) or control peptide in mice bearing subcutaneous tumors derived from the injection of Id4-driven mouse GSCs. Whole-body biofluorescence images were obtained $24 \mathrm{~h}$ after injection of Q-GSCT and Q-control peptides. (b) In vivo biodistribution of Q-Dot 800-conjugated GSCT or control peptide in orthotopic brain tumor models. Whole-body biofluorescence images were obtained 4 days after injection of Q-GSCT and Q-control peptides in mice bearing orthotopic brain tumors derived from the injection of Id4-driven mouse GSCs. (c) Fluorescence images of Q-GSCT peptides in tumors and organs extracted from mice bearing subcutaneous tumors are shown in Figure 3(a). (d) Fluorescence images of Q-GSCT peptides in brains extracted from mice bearing orthotopic tumors are shown in Figure 3(b). With reprint permission from Elsevier.

The development of multifunctional reporter platforms has the potential to provide both diagnostic and therapeutic capabilities in cancer treatment.

\section{Discussion}

Researchers have tried for decades to understand cancer development in the context of therapeutic strategies. The CSC model provides an attractive concept to explain why cancer contains cells resistant to chemo- and radiotherapies $[2,3]$. A minority population of CSCs has the ability to selfrenew, whereas the majority of cancer cells have the limited or no ability to proliferate in breast and brain tumors [59]. There has been acceptance of the idea that the remaining tumor cells after anticancer therapy have a distinct molecular phenotype that confers resistance to the therapies $[2,3]$.
CSCs are tumorigenic and possess the metastatic phenotype. Interestingly, many studies show that cells of CSC phenotypes also express stem/progenitor-associated genes which may suggest the possible link between CSCs and normal stem cells. A comparison of the biomarkers of CSC and normal stem cell was shown in Table 1. CSCs share common features with normal stem cells, most obviously the characteristic of self-renewal. Current knowledge indicates that a specialized microenvironment, the stem cell niche, is one of the factors regulating normal stem cell maintenance and self-renewal [59]. In analogy to the normal intestinal stem cell niche, researchers conclude that there is a CSC niche that is probably composed of a combination of stromal cells and more differentiated progeny and delivers crucial signals to the CSCs. Tumors may arise through a series of mutations that disrupt normal development 


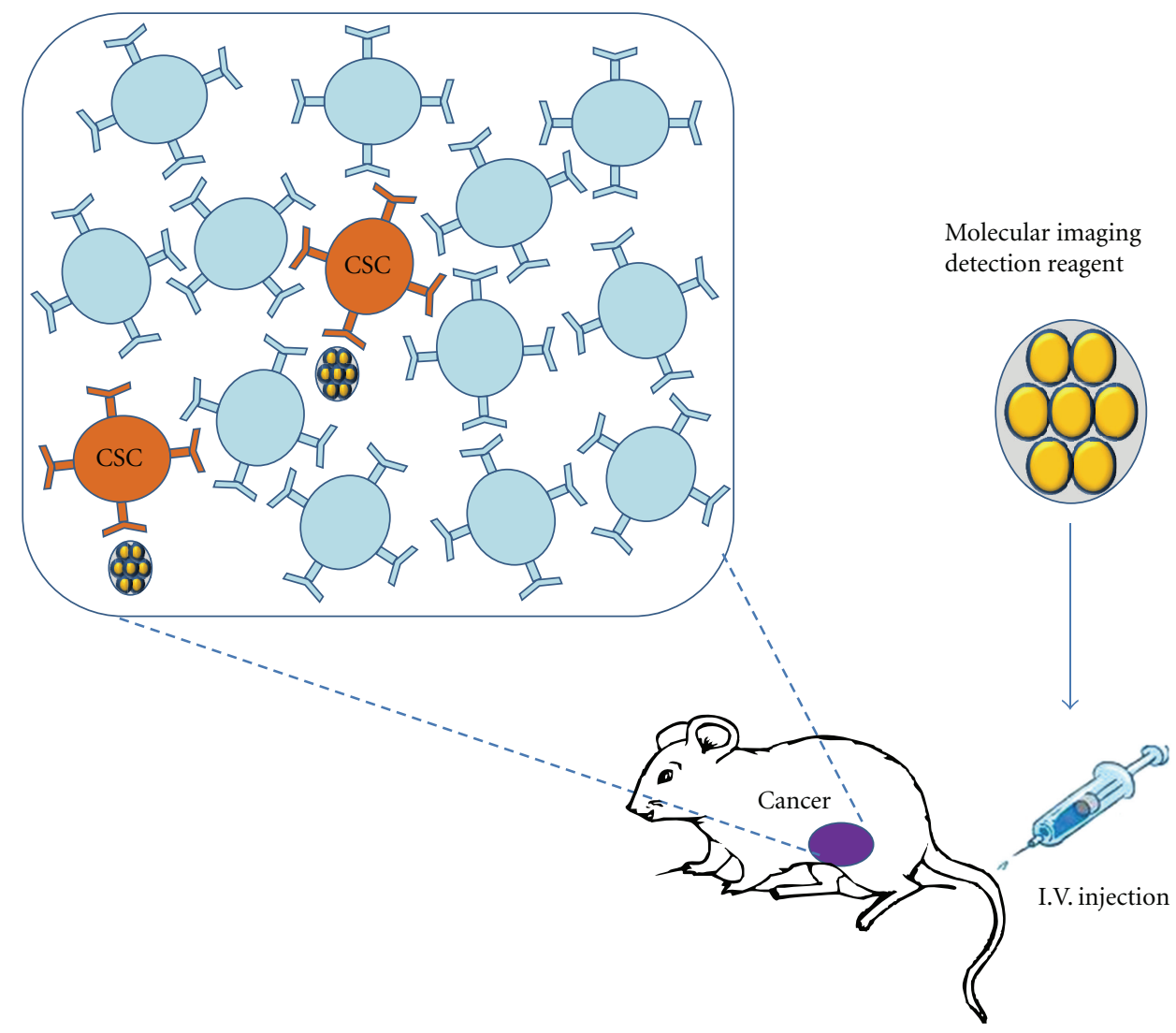

FIGURE 4: Paradigm of the application of molecular imaging in CSCs detection based on cancer stem cell model. Red and blue indicate cancer stem cells (CSCs) and non-CSCs, respectively.

pathways, and a population of continuously self-renewing cells must arise [59]. Genes (e.g., Bmil 1) that program self-renewal rather than differentiation are likely to be candidate oncogenes [60-62]. Exploring the mechanism regulating stemness features of CSCs in the tumorigenic process will benefit developing treatment aimed at destroying CSCs without adversely affecting normal stem cell characteristics.

CSCs may often constitute only a small population of tumor mass thus, there is a need for imaging modalities and probes that provide high-sensitivity and high-imaging resolution. Molecular imaging is emerging as a promising strategy with which to shed light on the clinical application. This technique has the potential to become a powerful technique for monitoring the history and the fate of CSCs and for evaluating response to therapy. The precise real-time imaging of CSCs in tumors at molecular and cellular levels is challenging. Single-luciferase models require animals to be injected with the luciferin substrate, and the limitation of the signal in xenograft model of human neoplasia requires expression of luciferase is at least 2,500 cells for proper detection [63]. The good option may be concurrently employing more than one fluorophore and highly sensitive detectors. MRI detects the presence of SPIO contrast agents regardless of whether the cells are alive or dead; it is also challenged to count the number of SPIO labeld cells in MRI on account of the contrast agent dilution during cell division, transfer to other cells, and the exist of other source of iron in tissue. To overcome limitations, the multimodality of imaging techniques (e.g., magnetic and optical) can be developed for applications in medicine.

For noninvasive imaging of CSCs as well as CSCspecific therapies, the targeting of cell surface proteins using antibodies or other receptor ligands is particularly relevant (Figure 4). Noninvasive imaging of CSCs would be critical in the management of malignant cancer disease, for example, for determining prognosis of patients, using as a diagnosis parameter, and monitoring therapeutic efficacy.

\section{Conclusions}

There is increasing evidence to support the existence of CSC that is identified by several markers, including CD133, CD44, CD24, and ALDH, or by selecting for the SP cells. Interestingly, no single marker is exclusively expressed by CSCs. Thus, in order to identify CSCs, the various combinations of different biomarkers may be possible. Targeting and elimination of the small population of CSCs hold attractive cancer treatment and avoid tumor recurrence.

Tracking of CSCs in vivo may facilitate the search for novel therapeutic approaches that improve radiation therapy outcome. The development of therapeutic agents specifically targeting CSCs together with a revised radiotherapy or chemotherapy protocol will alter the traditional poor 
prognosis of tumor patients. Novel drugs that selectively target CSCs offer great promise for more completed cancer treatment; however, designing and finding such drugs remain a great challenge.

Still, much work needs to be done in order to completely understand the origin of CSCs, as well as the mechanisms regulating their stemness features in the tumorigenic process and their increased resistance to chemotherapy and radiotherapy. Although the tracking of circulating CSCs is still hampered by technological challenges, we expect personalized diagnosis and therapy of cancers to be established based on increased studies and applications of molecular imaging of biomarkers in cancer stem-like cells.

\section{Abbreviations}

$\begin{array}{ll}\text { CSCs: } & \text { Cancer stem cells } \\ \text { CICs: } & \text { Cancer initiating cells } \\ \text { T-ICs: } & \text { Tumor-initiating cells } \\ \text { SP: } & \text { Side population } \\ \text { PSCA: } & \text { Prostate stem cell antigen } \\ \text { EpCAM: } & \text { Epithelial cell adhesion molecule } \\ \text { ESA: } & \text { Epithelial-specific antigen } \\ \text { PET: } & \text { Positron emission tomography } \\ \text { BLI: } & \text { Bioluminescence imaging } \\ \text { MRI: } & \text { Magnetic resonance imaging } \\ \text { TCL-SPIONs: } & \text { Thermally cross-linked superparamagnetic } \\ & \text { iron oxide nanoparticles } \\ \text { FMT: } & \text { Near-infrared fluorescence molecular } \\ & \text { tomography. }\end{array}$

\section{Conflict of Interests}

The authors declare that they have no conflict of interests.

\section{Acknowledgments}

This work is partly sponsored by Grants from the Zhejiang Provincial Natural Science Foundation of China (Z2110230), Health Bureau of Zhejiang Province (2010ZA075, 2011ZDA013), National Science Foundation of China (NSFC) (nos. $81101023,81170306,81173468$ ), and Ministry of Science and Technology of China (2011CB504400, 2012BAI13B06).

\section{References}

[1] R. Siegel, E. Ward, O. Brawley, and A. Jemal, "Cancer statistics, 2011: the impact of eliminating socioeconomic and racial disparities on premature cancer deaths," CA Cancer Journal for Clinicians, vol. 61, no. 4, pp. 212-236, 2011.

[2] J. R. Benson, I. Jatoi, M. Keisch, F. J. Esteva, A. Makris, and V. C. Jordan, "Early breast cancer," The Lancet, vol. 373, no. 9673, pp. 1463-1479, 2009.

[3] K. Kai, Y. Arima, T. Kamiya, and H. Saya, "Breast cancer stem cells," Breast Cancer, vol. 17, no. 2, pp. 80-85, 2010.

[4] A. Kabashima, H. Higuchi, H. Takaishi et al., "Side population of pancreatic cancer cells predominates in TGF- $\beta$-mediated epithelial to mesenchymal transition and invasion," International Journal of Cancer, vol. 124, no. 12, pp. 2771-2779, 2009.
[5] C. Hirschmann-Jax, A. E. Foster, G. G. Wulf et al., "A distinct "side population" of cells with high drug efflux capacity in human tumor cells," Proceedings of the National Academy of Sciences of the United States of America, vol. 101, no. 39, pp. 14228-14233, 2004.

[6] C. Hirschmann-Jax, A. E. Foster, G. G. Wulf, M. A. Goodell, and M. K. Brenner, "A distinct "side population" of cells in human tumor cells: implications for tumor biology and therapy," Cell Cycle, vol. 4, no. 2, pp. 203-205, 2005.

[7] C. T. Jordan, M. L. Guzman, and M. Noble, "Cancer stem cells," New England Journal of Medicine, vol. 355, no. 12, pp. 1253-1261, 2006.

[8] J. E. Visvader and G. J. Lindeman, "Cancer stem cells in solid tumours: accumulating evidence and unresolved questions," Nature Reviews Cancer, vol. 8, no. 10, pp. 755-768, 2008.

[9] L. Ricci-Vitiani, D. G. Lombardi, E. Pilozzi et al., "Identification and expansion of human colon-cancer-initiating cells," Nature, vol. 445, no. 7123, pp. 111-115, 2007.

[10] C. A. O’Brien, A. Pollett, S. Gallinger, and J. E. Dick, "A human colon cancer cell capable of initiating tumour growth in immunodeficient mice," Nature, vol. 445, no. 7123, pp. 106$110,2007$.

[11] T. Lapidot, C. Sirard, J. Vormoor et al., "A cell initiating human acute myeloid leukaemia after transplantation into SCID mice," Nature, vol. 367, no. 6464, pp. 645-648, 1994.

[12] D. Bonnet and J. E. Dick, "Human acute myeloid leukemia is organized as a hierarchy that originates from a primitive hematopoietic cell," Nature Medicine, vol. 3, no. 7, pp. 730737, 1997.

[13] S. K. Singh, C. Hawkins, I. D. Clarke et al., "Identification of human brain tumour initiating cells," Nature, vol. 432, no. 7015, pp. 396-401, 2004.

[14] M. T. Chiao, Y. C. Yang, W. Y. Cheng, C. C. Shen, and J. L. Ko, "CD133+ glioblastoma stem-like cells induce vascular mimicry in vivo," Current Neurovascular Research, vol. 8, no. 3, pp. 210-219, 2011.

[15] M. Tabuse, S. Ohta, Y. Ohashi et al., "Functional analysis of HOXD9 in human gliomas and glioma cancer stem cells," Molecular Cancer, vol. 10, article 60, 2011.

[16] J. Ferlay, H. R. Shin, F. Bray, D. Forman, C. Mathers, and D. M. Parkin, "Estimates of worldwide burden of cancer in 2008: GLOBOCAN 2008," International Journal of Cancer, vol. 127, no. 12, pp. 2893-2917, 2010.

[17] C. Ginestier, M. H. Hur, E. Charafe-Jauffret et al., "ALDH1 is a marker of normal and malignant human mammary stem cells and a predictor of poor clinical outcome," Cell Stem Cell, vol. 1, no. 5, pp. 555-567, 2007.

[18] M. Al-Hajj, M. S. Wicha, A. Benito-Hernandez, S. J. Morrison, and M. F. Clarke, "Prospective identification of tumorigenic breast cancer cells," Proceedings of the National Academy of Sciences of the United States of America, vol. 100, no. 7, pp. 3983-3988, 2003.

[19] M. Cordenonsi, F. Zanconato, L. Azzolin et al., "The hippo transducer TAZ confers cancer stem cell-related traits on breast cancer cells," Cell, vol. 147, no. 4, pp. 759-772, 2011.

[20] A. Eramo, F. Lotti, G. Sette et al., "Identification and expansion of the tumorigenic lung cancer stem cell population," Cell Death and Differentiation, vol. 15, no. 3, pp. 504-514, 2008.

[21] V. Levina, A. M. Marrangoni, R. DeMarco, E. Gorelik, and A. E. Lokshin, "Drug-selected human lung cancer stem cells: cytokine network, tumorigenic and metastatic properties," PLoS One, vol. 3, no. 8, Article ID e3077, 2008.

[22] M. M. Ho, A. V. Ng, S. Lam, and J. Y. Hung, "Side population in human lung cancer cell lines and tumors is enriched with 
stem-like cancer cells," Cancer Research, vol. 67, no. 10, pp. 4827-4833, 2007.

[23] H. Iinuma, T. Watanabe, K. Mimori et al., "Clinical significance of circulating tumor cells, including cancer stem-like cells, in peripheral blood for recurrence and prognosis in patients with dukes' stage B and C colorectal cancer," Journal of Clinical Oncology, vol. 29, no. 12, pp. 1547-1555, 2011.

[24] L. Vermeulen, M. Todaro, F. de Sousa Mello et al., "Singlecell cloning of colon cancer stem cells reveals a multi-lineage differentiation capacity," Proceedings of the National Academy of Sciences of the United States of America, vol. 105, no. 36, pp. 13427-13432, 2008.

[25] P. Dalerba, S. J. Dylla, I. K. Park et al., "Phenotypic characterization of human colorectal cancer stem cells," Proceedings of the National Academy of Sciences of the United States of America, vol. 104, no. 24, pp. 10158-10163, 2007.

[26] L. Vermeulen, F. de Sousa E Melo, M. van der Heijden et al., "Wnt activity defines colon cancer stem cells and is regulated by the microenvironment," Nature Cell Biology, vol. 12, no. 5, pp. 468-476, 2010.

[27] S. Beck, X. Jin, J. Yin et al., "Identification of a peptide that interacts with Nestin protein expressed in brain cancer stem cells," Biomaterials, vol. 32, no. 33, pp. 8518-8528, 2011.

[28] C. Yu, Z. Yao, J. Dai et al., "ALDH activity indicates increased tumorigenic cells, but not cancer stem cells, in prostate cancer cell lines," In Vivo, vol. 25, no. 1, pp. 69-76, 2011.

[29] V. K. Rajasekhar, L. Studer, W. Gerald, N. D. Socci, and H. I. Scher, "Tumour-initiating stem-like cells in human prostate cancer exhibit increased NF- $\kappa \mathrm{B}$ signalling," Nature Communications, vol. 2, article 162, 2011.

[30] P. A. Philip, M. Mooney, D. Jaffe et al., "Consensus report of the national cancer institute clinical trials planning meeting on pancreas cancer treatment," Journal of Clinical Oncology, vol. 27, no. 33, pp. 5660-5669, 2009.

[31] M. J. Moore, D. Goldstein, J. Hamm et al., "Erlotinib plus gemcitabine compared with gemcitabine alone in patients with advanced pancreatic cancer: a phase III trial of the National Cancer Institute of Canada Clinical Trials Group," Journal of Clinical Oncology, vol. 25, no. 15, pp. 1960-1966, 2007.

[32] T. Reya, S. J. Morrison, M. F. Clarke, and I. L. Weissman, "Stem cells, cancer, and cancer stem cells," Nature, vol. 414, no. 6859, pp. 105-111, 2001.

[33] J. Dorado, E. Lonardo, I. Miranda-Lorenzo, and C. Heeschen, "Pancreatic cancer stem cells: new insights and perspectives," Journal of Gastroenterology, vol. 46, no. 8, pp. 966-973, 2011.

[34] C. Li, D. G. Heidt, P. Dalerba et al., "Identification of pancreatic cancer stem cells," Cancer Research, vol. 67, no. 3, pp. 1030 1037, 2007.

[35] M. Rovira, S. G. Scott, A. S. Liss, J. Jensen, S. P. Thayer, and S. D. Leach, "Isolation and characterization of centroacinar/terminal ductal progenitor cells in adult mouse pancreas," Proceedings of the National Academy of Sciences of the United States of America, vol. 107, no. 1, pp. 75-80, 2010.

[36] M. P. Kim, J. B. Fleming, H. Wang et al., "ALDH activity selectively defines an enhanced tumor-initiating cell population relative to CD133 expression in human pancreatic adenocarcinoma," PLoS One, vol. 6, no. 6, Article ID e20636, 2011.

[37] B. I. Carr, "Hepatocellular carcinoma: current management and future trends," Gastroenterology, vol. 127, supplement 1, no. 5, pp. S218-S224, 2004.
[38] W. T. Kassahun, J. Fangmann, J. Harms, J. Hauss, and M. Bartels, "Liver resection and transplantation in the management of hepatocellular carcinoma: a review," Experimental and Clinical Transplantation, vol. 4, no. 2, pp. 549-558, 2006.

[39] T. K. W. Lee, A. Castilho, V. C. H. Cheung, K. H. Tang, S. $\mathrm{Ma}$, and I. O. L. Ng, "CD24+ liver tumor-initiating cells drive self-renewal and tumor initiation through STAT3-mediated NANOG regulation," Cell Stem Cell, vol. 9, no. 1, pp. 50-63, 2011.

[40] A. Hadnagy, L. Gaboury, R. Beaulieu, and D. Balicki, "SP analysis may be used to identify cancer stem cell populations," Experimental Cell Research, vol. 312, no. 19, pp. 3701-3710, 2006.

[41] H. Liu, M. R. Patel, J. A. Prescher et al., "Cancer stem cells from human breast tumors are involved in spontaneous metastases in orthotopic mouse models," Proceedings of the National Academy of Sciences of the United States of America, vol. 107, no. 42, pp. 18115-18120, 2010.

[42] J. V. Leyton, T. Olafsen, E. J. Lepin et al., "Humanized radioiodinated minibody for imaging of prostate stem cell antigenexpressing tumors," Clinical Cancer Research, vol. 14, no. 22, pp. 7488-7496, 2008.

[43] R. McClelland, E. Wauthier, T. Tallheden, L. M. Reid, and E. $\mathrm{Hsu}$, "In Situ labeling and magnetic resonance imaging of transplanted human hepatic stem cells," Molecular Imaging and Biology, vol. 13, no. 5, pp. 911-922, 2011.

[44] C. Tsurumi, N. Esser, E. Firat et al., "Non-invasive in vivo imaging of tumor-associated cd133/prominin," PLoS One, vol. 5, no. 12, Article ID e15605, 2010.

[45] M. Hubank and D. G. Schatz, "Identifying differences in mRNA expression by representational difference analysis of cDNA," Nucleic Acids Research, vol. 22, no. 25, pp. 5640-5648, 1994.

[46] R. E. Reiter, Z. Gu, T. Watabe et al., "Prostate stem cell antigen: a cell surface marker overexpressed in prostate cancer," Proceedings of the National Academy of Sciences of the United States of America, vol. 95, no. 4, pp. 1735-1740, 1998.

[47] Z. Gu, G. Thomas, J. Yamashiro et al., "Prostate stem cell antigen (PSCA) expression increases with high gleason score, advanced stage and bone metastasis in prostate cancer," Oncogene, vol. 19, no. 10, pp. 1288-1296, 2000.

[48] J. V. Leyton, T. Olafsen, M. A. Sherman et al., "Engineered humanized diabodies for microPET imaging of prostate stem cell antigen-expressing tumors," Protein Engineering, Design and Selection, vol. 22, no. 3, pp. 209-216, 2009.

[49] E. J. Lepin, J. V. Leyton, Y. Zhou et al., "An affinity matured minibody for PET imaging of prostate stem cell antigen (PSCA)-expressing tumors," European Journal of Nuclear Medicine and Molecular Imaging, vol. 37, no. 8, pp. 1529-1538, 2010.

[50] C. A. Foss, J. J. Fox, G. Feldmann et al., "Radiolabeled anticlaudin 4 and anti-prostate stem cell antigen: initial imaging in experimental models of pancreatic cancer," Molecular Imaging, vol. 6, no. 2, pp. 131-139, 2007.

[51] Y. Yoshii, T. Furukawa, Y. Kiyono et al., "Internal radiotherapy with copper-64-diacetyl-bis ( $\mathrm{N}^{4}$-methylthiosemicarbazone) reduces $\mathrm{CD}_{133^{+}}$highly tumorigenic cells and metastatic ability of mouse colon carcinoma," Nuclear Medicine and Biology, vol. 38, no. 2, pp. 151-157, 2011.

[52] O. K. Okamoto and J. F. Perez, "Targeting cancer stem cells with monoclonal antibodies: a new perspective in cancer therapy and diagnosis," Expert Review of Molecular Diagnostics, vol. 8, no. 4, pp. 387-393, 2008. 
[53] E. K. Lim, H. O. Kim, E. Jang et al., "Hyaluronan-modified magnetic nanoclusters for detection of CD44-overexpressing breast cancer by MR imaging," Biomaterials, vol. 32, no. 31, pp. 7941-7950, 2011.

[54] A. Z. Wang, V. Bagalkot, C. C. Vasilliou et al., "Superparamagnetic iron oxide nanoparticle-aptamer bioconjugates for combined prostate cancer imaging and therapy," ChemMedChem, vol. 3, no. 9, pp. 1311-1315, 2008.

[55] E. Vlashi, K. Kim, C. Lagadec et al., "In vivo imaging, tracking, and targeting of cancer stem cells," Journal of the National Cancer Institute, vol. 101, no. 5, pp. 350-359, 2009.

[56] H. Y. Ko, K. J. Choi, C. H. Lee, and S. Kim, "A multimodal nanoparticle-based cancer imaging probe simultaneously targeting nucleolin, integrin $\alpha \mathrm{v} \beta 3$ and tenascin-C proteins," Biomaterials, vol. 32, no. 4, pp. 1130-1138, 2011.

[57] L. Garzia, I. Andolfo, E. Cusanelli et al., "MicroRNA-199b-5p impairs cancer stem cells through negative regulation of HES1 in medulloblastoma," PLoS One, vol. 4, no. 3, Article ID e4998, 2009.

[58] V. Ponomarev, M. Doubrovin, I. Serganova et al., "A novel triple-modality reporter gene for whole-body fluorescent, bioluminescent, and nuclear noninvasive imaging," European Journal of Nuclear Medicine and Molecular Imaging, vol. 31, no. 5, pp. 740-751, 2004.

[59] M. F. Clarke and M. Fuller, "Stem cells and cancer: two faces of eve," Cell, vol. 124, no. 6, pp. 1111-1115, 2006.

[60] A. V. Molofsky, R. Pardal, T. Iwashita, I. K. Park, M. F. Clarke, and S. J. Morrison, "Bmi-1 dependence distinguishes neural stem cell self-renewal from progenitor proliferation," Nature, vol. 425, no. 6961, pp. 962-967, 2003.

[61] I. K. Park, D. Qian, M. Kiel et al., "Bmi-1 is required for maintenance of adult self-renewing haematopoietic stem cells," Nature, vol. 423, no. 6937, pp. 302-305, 2003.

[62] J. Lessard and G. Sauvageau, "Bmi-1 determines the proliferative capacity of normal and leukaemic stem cells," Nature, vol. 423, no. 6937, pp. 255-260, 2003.

[63] T. J. Sweeney, V. Mailander, A. A. Tucker et al., "Visualizing the kinetics of tumor-cell clearance in living animals," Proceedings of the National Academy of Sciences of the United States of America, vol. 96, no. 21, pp. 12044-12049, 1999.

[64] H. Niwa, J. I. Miyazaki, and A. G. Smith, "Quantitative expression of Oct-3/4 defines differentiation, dedifferentiation or self-renewal of ES cells," Nature Genetics, vol. 24, no. 4, pp. 372-376, 2000.

[65] J. A. Thomson, "Embryonic stem cell lines derived from human blastocysts," Science, vol. 282, no. 5391, pp. 1145-1147, 1998.

[66] C. Calabrese, H. Poppleton, M. Kocak et al., "A perivascular niche for brain tumor stem cells," Cancer Cell, vol. 11, no. 1, pp. 69-82, 2007.

[67] S. Pece, D. Tosoni, S. Confalonieri et al., "Biological and molecular heterogeneity of breast cancers correlates with their cancer stem cell content," Cell, vol. 140, no. 1, pp. 62-73, 2010.

[68] P. Eirew, J. Stingl, A. Raouf et al., "A method for quantifying normal human mammary epithelial stem cells with in vivo regenerative ability," Nature Medicine, vol. 14, no. 12, pp. 1384-1389, 2008. 


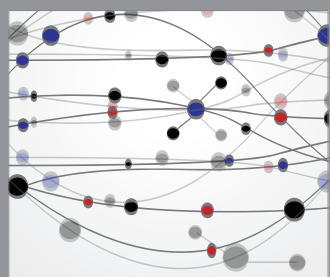

The Scientific World Journal
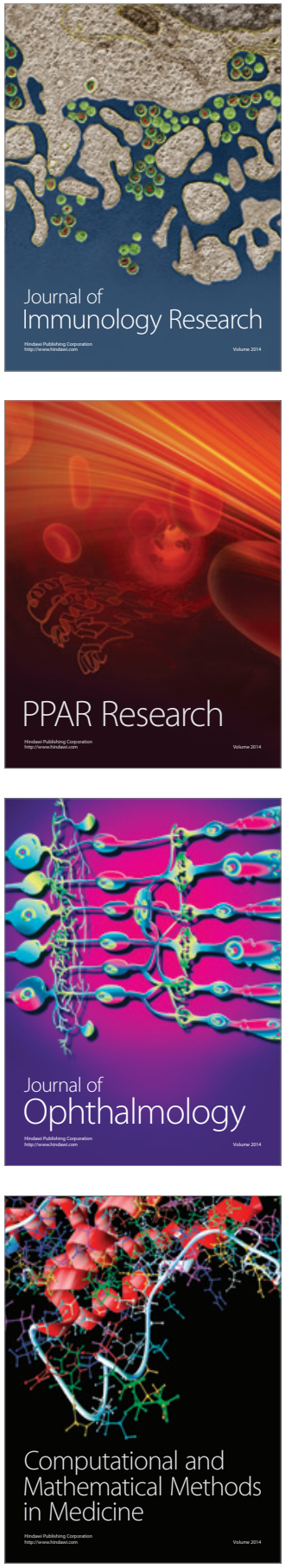

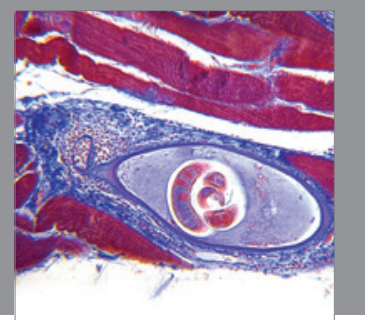

Gastroenterology

Research and Practice
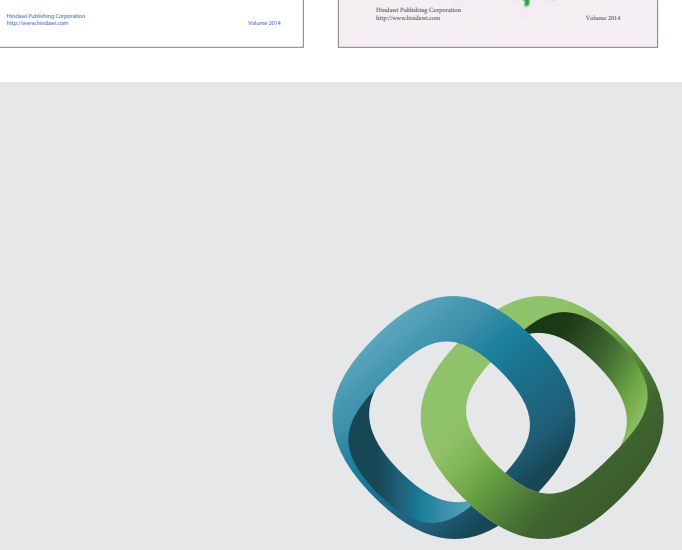

\section{Hindawi}

Submit your manuscripts at

http://www.hindawi.com
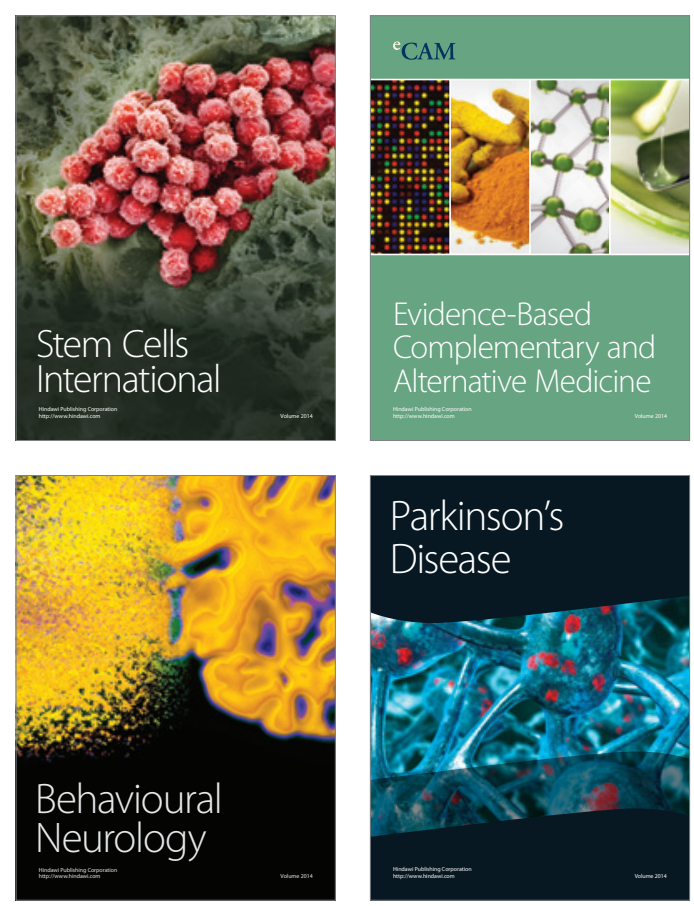

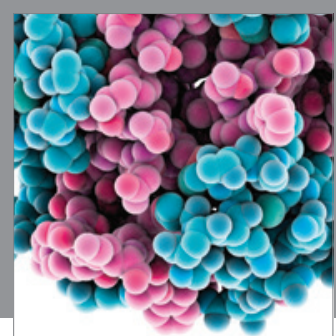

Journal of
Diabetes Research

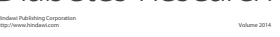

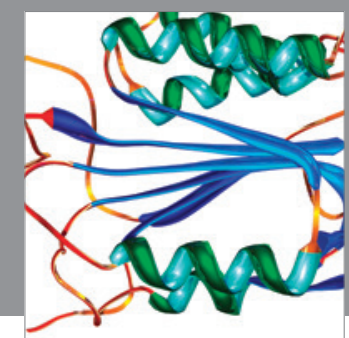

Disease Markers
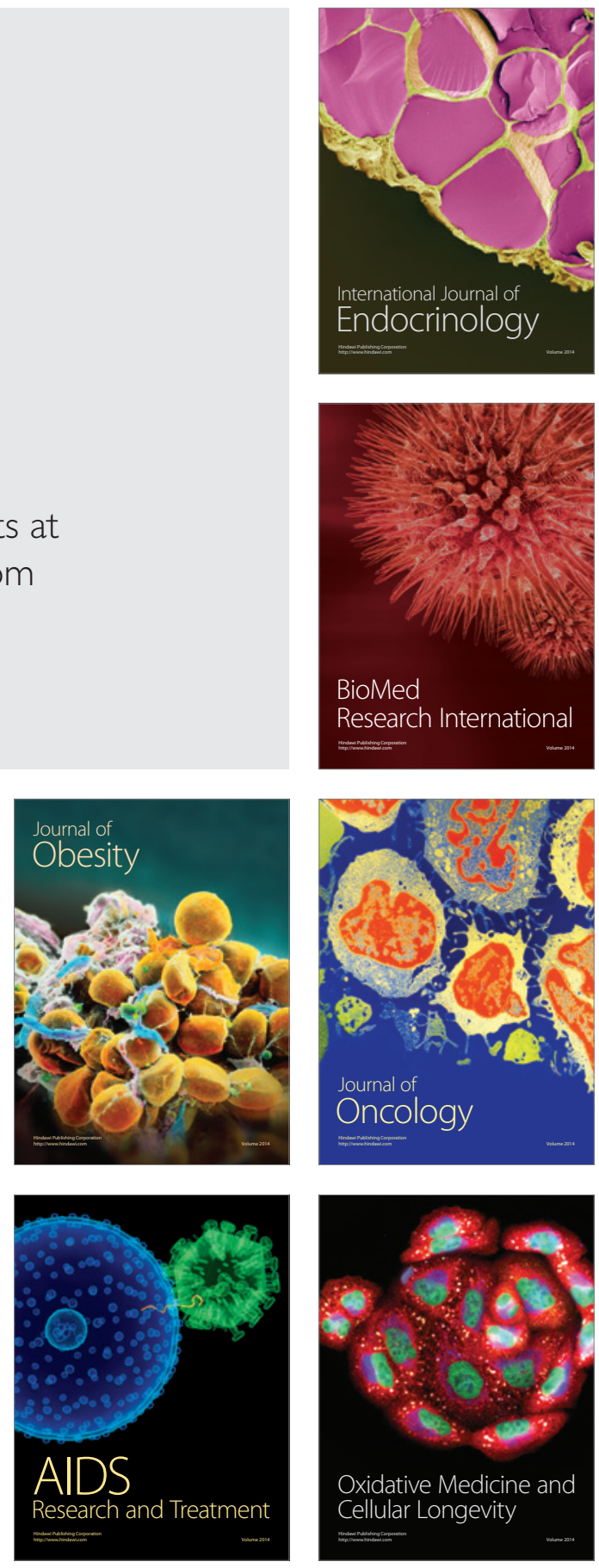